\title{
Forecasting of poor visibility episodes in the vicinity of Tenerife Norte Airport
}

\author{
Sergio Fernández-González ${ }^{\text {a, }}$, Pedro Bolgiani ${ }^{\text {b }}$, Javier Fernández-Villares a, Pino González ${ }^{\text {a }}$, \\ Alejandro García-Gil ${ }^{a}$, Juan Carlos Suárez ${ }^{a}$, Andrés Merino ${ }^{c}$ \\ ${ }^{a}$ State Meteorological Agency (AEMET), Spain \\ ${ }^{\mathrm{b}}$ Department of Earth Physics and Astrophysics, Faculty of Physics, Complutense University of Madrid, Spain

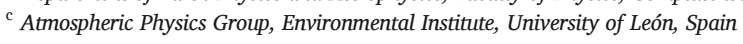

\section{A R T ICLE INFO}

\section{Keywords:}

Aviation safety

Fog

Poor visibility

Mesoscale modelling

MSG

\begin{abstract}
A B S T R A C T
Aviation safety is a priority that may be compromised by adverse weather conditions. This is the case for poor visibility in the vicinity of airports, which can pose a risk during takeoff and landing. For airports that are prone to fog because of their location, an accurate forecast of poor-visibility episodes is vital. However, the forecasting of low clouds is still a challenge in numerical weather prediction, especially when an airport is near complex terrain for which the use of non-hydrostatic mesoscale models is mandatory. All these factors are present at Tenerife Norte Airport, which is commonly affected by poor visibility from low clouds related to persistent trade winds and moist flows from the Atlantic Ocean.

In this paper, several methods for estimating visibility based on mesoscale model outputs are tested. Use of the HARMONIE-AROME model is encouraged because of its excellent performance in the detection of poor-visibility episodes (False Alarm Ratio $=0.34-0.38$; Frequency Of Misses $=0.22-0.38$, depending on the model version and method used). In addition, the use of satellite application facilities is proposed for the nowcasting of low clouds affecting the airport area. Specifically, we used products that estimate cloud type, cloud top altitude, and integrated water vapor content in the boundary layer. Finally, an application is presented for the monitoring of weather conditions in real time to estimate poor-visibility risk.
\end{abstract}

\section{Introduction}

Air traffic management can be affected by adverse weather conditions such as icing, wind shear, poor visibility and turbulence (Dey, 2018). Particularly, poor visibility around airports affects flight operations by reducing runway and taxiway capacities, which causes flight delays, diversions to other airports, or even cancellations (Bergot et al., 2007). The impact of poor-visibility events has increased in recent decades because of an increase in air traffic (Gultepe et al., 2007).

Poor-visibility events are defined as fog when surface horizontal visibility is $<1000 \mathrm{~m}$, and as mist when that visibility is between 1000 and $5000 \mathrm{~m}$ (WMO, 2011). These episodes are caused by the suspension of cloud droplets (of radii $1-40 \mu \mathrm{m}$ ) near the surface. According to Pagowski et al. (2004), the most common fog types are radiation (caused by thermal radiation cooling during clear sky nights), advection (which can occur during warm air advection over a colder surface), and orographic (when air cools adiabatically when lifted by oro- graphic forcing over a mountain slope). Poor visibility can also be related to precipitation (Fedorova et al., 2013).

When visibility falls below a certain threshold, poor-visibility procedures must be activated by airport managers to ensure aviation safety. During fog events, air traffic controllers may reduce taxiway occupation, prolong periods between takeoffs and landings, or even suspend airport operations to avoid runway incursions and other possible incidents or accidents (Guijo-Rubio et al., 2018). Also, missed approach rates are higher, which adds workload and stress to the personnel involved. Therefore, an accurate forecast of poor-visibility episodes affecting airports is vital because of their impacts on flight planning and aviation safety (da Rocha et al., 2015). In this regard, it is crucial to have visibility forecasts as accurate as possible $24 \mathrm{~h}$ in advance in order to issue a Terminal Aerodrome Forecast (TAF).

However, the estimation of visibility remains a challenge for numerical weather prediction models. This challenge is greater for airports in complex terrain areas, where the use of mesoscale models with high resolution is indispensable. Fog formation and dissipation depends mainly on microphysical processes, wind, humidity and temperature in

\footnotetext{
* Corresponding author at: Delegación Territorial de AEMET en Cantabria, C/ Ricardo Lorenzo, 0, CP 39012 Santander, Spain.

Email address: sfernandezg@aemet.es (S. Fernández-González)
} 
the planetary boundary layer (PBL) (Stolaki et al., 2012; Payra and Mohan, 2014). Some of these variables must be parameterized, so the main sources of error in numerical models are initial conditions and physical parameterizations (Fernández-González et al., 2017). The most common method to evaluate uncertainty associated with a forecast is the perturbation of initial conditions. However, perturbations require time to grow, so they are used mainly for medium-range forecasts (Buizza et al., 1999). For short-term forecasts, it is advisable to use different models or parameterizations to evaluate prediction uncertainty, because this facilitates adequate spread in a short lead time (Stensrud et al., 2000).

Forecasts from mesoscale models can be complemented by the use of satellite products for the nowcasting of fog episodes (Ahmed et al., 2015). Fog detection with satellite imagery has been attempted in recent decades using various approaches (Nilo et al., 2018). For instance, fog and low clouds can be detected by their reflectance characteristics in the visible band. During nighttime, the difference between brightness temperatures in the 10.8 and $3.7 \mu \mathrm{m}$ channels allows the detection of low clouds, because fog droplets produce less emissivity in the $3.7 \mu \mathrm{m}$ channel than at $10.8 \mu \mathrm{m}$ (Gultepe et al., 2007). During daytime, information provided by infrared channels can be compared with visible channels for the detection of fog (Cermak and Bendix, 2008).

The aim of the present research was to provide a categorical forecast of the risk of poor-visibility conditions near Tenerife Norte Airport (hereafter, GCXO, the airport's International Civil Aviation Organization code). This was done using mesoscale models with a lead time of $24 \mathrm{~h}$ to improve TAF reliability. In addition, several products of the Nowcasting Satellite Application Facilities (NWC SAF, nwc-saf.eumetsat.int) are proposed to confirm/correct the mesoscale forecasts in real time, improving on information within Meteorological Terminal Air Reports (METAR), special reports (SPECI), and trend reports (TREND). GCXO was selected because of recurring fog; it is the most affected by this phenomenon among all the airports in the Canary Islands, with consequent great impact on flight operations. With over 4.7 million passengers in 2017, GCXO funnels most of the Spanish national air traffic to the island of Tenerife. The airport is also known for one of the worst accidents in aviation history. On 27 March 1977, two Boeing 747 jets collided on the runway, causing 583 fatalities. One of the key factors in this accident was poor visibility caused by dense fog. This event stresses the importance of investigating this type of weather phenomenon at GCXO, especially for its impacts on aviation safety.

\section{Study area}

GCXO is in the northeast of Tenerife, part of the Canary Islands (Fig. 1). The airport runway is oriented NW-SE at an elevation about $600 \mathrm{~m}$ above sea level (masl). It is between two mountain ranges whose elevations are higher than 1000 masl. Depending on wind direc- tion, flights use Runway 12 (R12, northwestern part of the airport) or Runway 30 (R30, in its southeast). One of the key features of this orographic setting is efficient channeling of flow from either the NW or SE, with a clear dominance of the first because of prevailing trade winds (northeasterly) in the area, which occur $>70 \%$ of the year.

The state meteorological agency (AEMET) of Spain has the capability to provide aeronautical meteorological services within the national airspace. Therefore, the staff of AEMET issue TAFs, which are forecasts of conditions at airports over the next $24 \mathrm{~h}$. Moreover, routine METARs are produced every half hour using observations at the airport. SPECI reports can be issued when observed meteorological conditions change suddenly. In addition, TREND reports must be issued when significant changes are expected in the next two hours. The purpose of our research was to help AEMET staff revise these reports, improving their reliability by making available more detailed information from mesoscale models and satellite products.

\section{Experimental design}

\subsection{Database}

We selected 14 poor-visibility episodes (Table 1) registered at GCXO during 2017 for validation. At least one episode per month was chosen to have events representative of all seasons of the year. In order to cover all the different types of poor visibility episodes that affect the GCXO airport, 4 episodes of SE wind and 10 of NW wind were selected, of which 2 the visibility was reduced by the passage of a cold front. According to several works, this sample number is sufficient for validating mesoscale models (Evans et al., 2012; Johnson and Wang, 2012).

In the validation, we used several instruments near R30, which is the representative runway of the airport. The instrumentation is composed of the following: an anemometer with Vaisala WAA15 wind speed (WSP) sensor and Vaisala WAV15 direction sensor; a Vaisala FD12 front dispersion sensor for measuring visibility and runway visual range; a Vaisala HMP155 thermo-hygrograph measuring temperature (T), dew point (Td), and relative humidity ( $\mathrm{RH})$.

\subsection{Mesoscale models}

We tested various mesoscale models. First, version 3.7.1. of the Weather Research and Forecasting (WRF) model was used to simulate the 14 episodes. WRF is a three-dimensional, nonhydrostatic model described by Skamarock and Klemp (2008). This model has been used in the forecasting of visibility near airports (Bang et al., 2008). Its simulations were initialized using initial conditions provided by the NCEP-GFS analysis with $1^{0} \times 1^{0}$ global grid and temporal resolution of $6 \mathrm{~h}$ (Saha, 2010). Simulations of each of the 14 days were run individually, initialized at 00:00 UTC with a hindcast period of $24 \mathrm{~h}$. Four nested do-
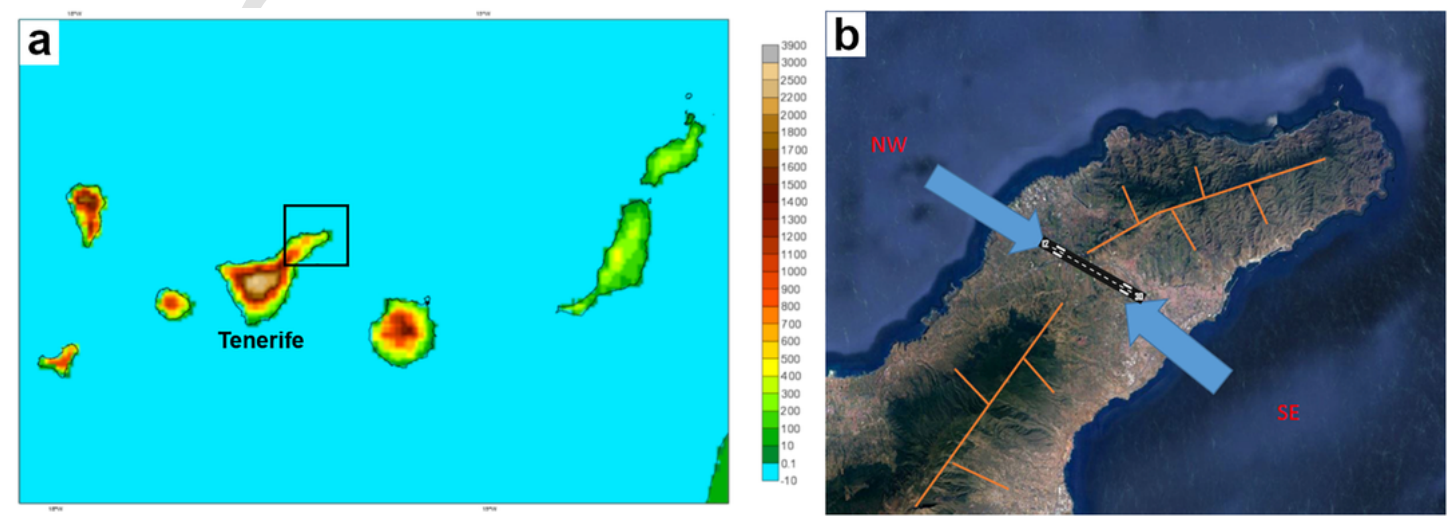

Fig. 1. Orography of Canary Islands (a). Location of GCXO on Tenerife (b). 
Table 1

Dates of the fourteen low visibility episodes in GCXO selected for the validation.

\begin{tabular}{cllllll}
\hline 201701 & 201702 & 201703 & 201704 & 201704 & 201705 & 201706 \\
21 & 19 & 24 & 02 & 26 & 31 & 15 \\
201707 & 201707 & 201708 & 201709 & 201710 & 201711 & 201712 \\
05 & 14 & 31 & 07 & 17 & 24 & 02 \\
\hline
\end{tabular}

mains were defined following a two-way nesting strategy. Spatial resolutions were $27 \mathrm{~km}$ for the outer domain (D01), 9 and $3 \mathrm{~km}$ respectively for D02 and D03, and $1 \mathrm{~km}$ for the inner domain (D04), centered over GCXO. Each domain had $100 \times 100$ grid points in the N-S and E-W directions. We defined 60 sigma levels for the atmosphere, with increasing resolution approaching the surface (8 vertical levels for the first $120 \mathrm{~m}$ above ground level (m AGL) and 20 for the first $1000 \mathrm{~m}$ AGL). For physical parameterizations, the Thompson six-class microphysics (Thompson et al., 2008), New Goddard long and short wave radiation (Chou et al., 2001), and Mellor-Yamada-Janjic PBL (Janjic, 1990) schemes were used.

Furthermore, two versions of the HARMONIE-AROME model were tested, namely, HARMONIE-AROME $38 \mathrm{~h} 1.2$ (H38), which was the operational mesoscale model of AEMET until June 2017, and HARMONIE-AROME 40h1.1 (H40), which is the agency's current operational mesoscale model. These models have a nonhydrostatic formulation and spectral representation (Seity et al., 2011). A detailed description of the configuration of these models is in Bengtsson et al. (2017). The operational forecasts of each poor-visibility episode, initialized at 00:00 UTC, were used in the validation procedure. These simulations had a lead time of $48 \mathrm{~h}$ but only the first $24 \mathrm{~h}$ were used. The models had a $2.5-\mathrm{km}$ horizontal grid resolution for the area around the Canary Islands, with 65 vertical levels and a model top of $10 \mathrm{hPa}$. The domain defined for models $\mathrm{H} 38$ and $\mathrm{H} 40$ are seen in Fig. 1a.

In the case of $\mathrm{H} 38$, descriptions of the assimilation component are in Fischer et al. (2005) and Brousseau et al. (2011). The assimilated observations are equivalent to those used by the European Centre for Medium Range Weather Forecasts ERA-Interim reanalysis (Dee et al., 2011). The surface parameterization scheme was version 7.2 of SURFEX (Masson et al., 2013).

Several changes were made to H40. The SURFEX surface scheme was updated to version 7.3 (Masson, 2016). The assimilation of H40 included Global Navigation Satellite System data for improving humidity observations (Sánchez Arriola et al., 2016). Following the recommendations of Nielsen et al. (2014), the cloud-inhomogeneity factor was changed from 0.7 to 1.0 , meaning that the cloud optical thickness was no longer reduced by $30 \%$ before cloud transmittance was computed (Nielsen and Gleeson, 2018). In addition, the Cuxart, Bougeault and Redelsperger turbulence scheme (Cuxart et al., 2000) was replaced by the turbulence scheme from the RACMO model (Lenderink and Holtslag, 2004).

\subsection{Validation methodology}

The validation period spanned 06:00 to 24:00 UTC on each of the 14 days of the study period. The first $6 \mathrm{~h}$ of each day were not considered in order to avoid errors from the spin-up period of the WRF model, because it was executed from a cold start. The first $6 \mathrm{~h}$ of $\mathrm{H} 38$ and H40 were also discarded to validate identical periods, although the warm start from a previous run cycle of HARMONIE-AROME allowed model outputs to be valid from the simulation start. As a result, the database used in the multi-category validation consists of a sample of $252 \mathrm{~h}$. Considering the high horizontal resolution of the mesoscale models and in order to avoid interpolation errors, the validation was performed using data of the grid point nearest the locations of the observations. A preliminary validation was carried out to confirm that the nearest grid point was the most representative of the weather at GCXO.
Model performance was first evaluated for the forecasting of meteorological variables most associated with fog formation. A validation based on continuous statistics was developed for T, Td, T-Td, RH, WSP and wind direction. Validation indexes selected for this task were the Bias, Mean Absolute Error (MAE), and correlation coefficient ( $r$ ), calculated as follows.

$$
\begin{aligned}
& \text { Bias }=\sum_{i=1}^{n}\left(M_{i}-O_{i}\right) \\
& M A E=\frac{1}{n} \sum_{i=1}^{n}\left|M_{i}-O_{i}\right| \\
& r=\frac{\sum_{i=1}^{n}\left(M_{i}-\bar{M}\right)\left(O_{i}-\bar{O}\right)}{\sqrt{\sum_{i=1}^{n}\left(M_{i}-\bar{M}\right)^{2}} \sqrt{\sum_{i=1}^{n}\left(O_{i}-\bar{O}\right)^{2}}}
\end{aligned}
$$

$M_{i}$ are modelled values, $O_{i}$ observed values, and $n$ is the number of hours in the study period. Bias compares modelled and observed values with the aim of determining if the model overestimates (Bias $>0$ ) or underestimates (Bias <0) a certain variable. On the other hand, the MAE evaluates the magnitude of simulation error, regardless of whether the model overestimates or underestimates. Finally, $r$ allows analysis of model performance over time, which is very important during fog episodes affected by the diurnal cycle.

Then, values obtained for the various indexes were normalized in order to compare them. We thereby determined a normalized index (NI). The ultimate purpose of this normalization was to develop a total index (TI) that summarized the results of the validation, thereby objectively determining the best model. The normalization was done by subtracting the average Bias/MAE/ $r$ from the obtained values, and then dividing the result by the same average. In the case of Bias, it is necessary to work with absolute values. To obtain a normalized $r$ we must also multiply by -1 because, opposite to the cases of Bias and MAE, values closer to 0 are poorer. Finally, the TI is computed by adding the values of normalized Bias, MAE and $r$ for each model. Negative TI values mean that the model has above average performance, i.e., the smaller the TI, the better the performance.

Subsequently, a multi-category validation for fog/mist/OK visibility events was carried out using contingency tables. According to definitions of the World Meteorological Organization (WMO, 2011), three categories were used for validation: fog (visibility $<1000 \mathrm{~m}$ ), mist $(1000 \mathrm{~m} \leq$ visibility $<5000 \mathrm{~m})$, and OK (visibility $\geq 5000 \mathrm{~m})$.

Visibility in GCXO airport can vary sharply in a few minutes, being one of the most difficult variables to predict by the numerical models. This is the reason why we used two methods to estimate visibility using the mesoscale models. The first estimates visibility (VISRH) using T, $\mathrm{Td}$ and $\mathrm{RH}$ as predictive variables, by means of an empirical algorithm defined by Doran et al. (1999). The second method gave an additional measure of visibility (VISHD) based on the hydrometeor concentration estimated by the model, following methods in Kunkel (1984), Stoelinga and Warner (1999), and Petersen and Nielsen (2000).

VISRH $(\mathrm{m})=9654000 \times \frac{T-T_{d}}{R H^{1.75}}$

$\operatorname{VISHD}(\mathrm{m})=\frac{-\ln (0.02)}{\left(\beta_{\text {clean }}+\beta_{\text {cloud }}+\beta_{\text {ice }}+\beta_{\text {rain }}+\beta_{\text {snow }}+\beta_{\text {graupel }}+\beta_{\text {aerosols }}\right)}$

where $\beta$ is the volume extinction coefficient of clean air (constant), cloud droplets, ice, rain, snow, graupel (depends on the concentration of each hydrometeor) and aerosols (based on the concentration of cloud condensation nuclei and $\mathrm{RH}$ at $2 \mathrm{~m}$ ). 
Finally, an additional method for evaluating poor-visibility risk is proposed, which is based on an algorithm that determines if certain thresholds are exceeded. Given the particular characteristics of fog events at GCXO, variables to develop the algorithm were selected ad hoc for that specific location. These were T-Td, RH, and WSP. Three algorithms were tested, using thresholds in Table 2. These thresholds are linked to Algorithm 1 (A1), Algorithm 2 (A2), and Algorithm 3 (A3).

Then, the contingency table defined in Table 3 was used to contrast the frequencies of forecast fog, mist and OK visibility episodes against observed ones (capital letters signify the sum of the corresponding row/ column).

Based on the methodology of Baldwin and Kain (2006) and López et al. (2007), the following skill scores were used. First, the Frequency Bias Index (FBI) was calculated. The FBI estimates the ratio of forecast vs. observed poor-visibility episodes. This score indicates whether the method has a tendency to over-forecast (FBI $>1$ ) or under-forecast $(\mathrm{FBI}<1)$ poor-visibility events. A value of 1 is the perfect score.

Additionally, the False Alarm Ratio (FAR) was estimated to evaluate the fraction of fog and mist episodes that were forecast but did not occur. A value of 0 is the perfect score.

Finally, the Frequency Of Misses (FOM) assesses the fraction of fog and mist episodes that were not forecast but did occur. A value of 0 is the perfect score.

$$
\mathrm{FBI}=\frac{M+N}{J+K} \quad \mathrm{FAR}=\frac{g+h}{M+N} \quad \mathrm{FOM}=\frac{c+f}{J+K}
$$

\subsection{Satellite products}

Based on our research, the use of satellite products is encouraged to complement the fog forecast provided by mesoscale models. We used several products from the Meteosat Second Generation, which is a geostationary satellite that provides continuous coverage of the study area. Specifically, we used the products "Cloud Type," "Cloud Top Altitude," and "Precipitable Water in Boundary Layer" from the NWC SAF. The Cloud Type product allows discernment of the cloud type and estimation of cloud thickness. By complementing this product with the Cloud Top Altitude, it is possible to estimate cloud top height. In cloud-free regions, the Precipitable Water in Boundary Layer product is able to estimate precipitable water (in $\mathrm{mm}$ ) integrated from the surface to $850 \mathrm{hPa}$ level. This product permits the estimation of moisture content in the stratum in which the cloudiness producing poor visibility at GCXO develops. A more detailed explanation of the above products is in Rípodas et al. (2016).

\section{Results and discussion}

\subsection{Conceptual model of fog development at GCXO}

GCXO is located on a mountain pass between two mountain ranges, which favors wind channeling from the NW or SE, depending on the location of the semi-permanent subtropical high. Thus, the geomorphological configuration is essential to the occurrence of such ageostrophic flow, which differs from the prevailing trade winds. The flow is forced to ascend the slope of a hill, adiabatically cooling so that saturation can be reached when there is substantial moisture. Sometimes, saturation is reached at an altitude lower than the elevation of GCXO, causing poor visibility at the airport. The uplift is often sharply interrupted by a trade wind inversion, limiting the cloud top to the same altitude as the base of the temperature inversion.

Poor-visibility events are frequent throughout the year but are particularly influential during summer, especially in June and July. A diurnal cycle is commonly observed, with the poor-visibility episodes more likely from sunset to dawn, when $\mathrm{T}$ and $\mathrm{Td}$ approach each other. The presence of the semi-permanent subtropical high generates anticyclonic subsidence in the Canary Island region, forming a thermal inversion that produces low stratocumulus. An example of a radiosonde profile over the island of Tenerife (a few kilometers SW of GCXO) is shown in Fig. 2, in which a strong trade wind inversion is evident around 1000 masl.

In winter, when the inversion is at an average altitude between 1200 and 2000 masl, the cloud base is usually above the runway and visibility does not tend to be much of a problem. However, during drizzle or moderate precipitation events, especially those associated with fronts from mid-latitude systems approaching from the NW, the formation of fog banks is not uncommon, and even the drizzle itself can reduce visibility. These events are not usually strongly dependent on the daily cycle but rather on the front arrival (AEMET, 2019).

In summer, the thermal inversion is normally at lower altitudes (often between 500 and 1000 masl), with a strong diurnal variability that presents the main obstacle to accurately predicting reduced visibility events. It is also in summer when trade winds from the NE are stronger and more frequent ( $\sim 90 \%$ of the time), with the aforementioned orography consistently channeling the flow to be mostly from the NW (Fig. 3a). This flow initiates moisture convergence in the PBL north of Tenerife island (Fig. 4a) and may produce low clouds (Fig. 5a) that are responsible for poor visibility at GCXO. In this scenario, poor visibility first reaches at R12 and later at R30.

Another meteorological situation, less frequent, occurs when the subtropical high becomes very weak or even dissipates. This scenario often weakens the pressure gradient around the Canary Islands. When this occurs, it is common to have a weak flow from the ENE-E that is channeled from SE by the terrain (Fig. 3b). This flow favors low-level moisture pooling south of Tenerife island (Fig. 4b) and cloud development from the southern side of the island to the airport (Fig. 5b). This causes poor visibility to occur earlier at the R30 threshold than at R12.

The conceptual model described in this paper is similar to the fog elucidated by Fedorova et al. (2013), which was also related to a thermal inversion above the trade winds. This shows that the products addressed in the following sections could be adapted to other locations with the same visibility problems.

\subsection{Validation of mesoscale models}

Before defining the products developed to forecast poor-visibility episodes, we validated the variables most associated with fog formation. In this validation, values of the variables estimated by the mesoscale models were compared with those observed at GCXO. The sample used in the validation is composed by observed visibility data

Table 2

Thresholds of the selected variables for defining fog/mist/OK conditions.

\begin{tabular}{|c|c|c|c|c|c|c|c|c|c|}
\hline & \multicolumn{3}{|l|}{ Algorithm 1} & \multicolumn{3}{|c|}{ Algorithm 2} & \multicolumn{3}{|c|}{ Algorithm 3} \\
\hline & $\mathrm{T}-\mathrm{Td}\left({ }^{\circ} \mathrm{C}\right)$ & RH (\%) & WSP (kt) & $\mathrm{T}-\mathrm{Td}\left({ }^{\circ} \mathrm{C}\right)$ & RH (\%) & WSP (kt) & $\mathrm{T}-\mathrm{Td}\left({ }^{\circ} \mathrm{C}\right)$ & RH (\%) & WSP (kt) \\
\hline Fog & $\leq 0.5$ & $\geq 96$ & $\geq 3$ & $\leq 0.3$ & $\geq 97.5$ & $\geq 4$ & $\leq 0.1$ & $\geq 99$ & $\geq 6$ \\
\hline Mist & $<1.5$ & $>90$ & $>1.5$ & $<1$ & $>94$ & $>2$ & $<0.5$ & $>96$ & $>3$ \\
\hline Clear & $>1.5$ & $<90$ & $<1.5$ & $>1$ & $<94$ & $<2$ & $>0.5$ & $<96$ & $<3$ \\
\hline
\end{tabular}


Table 3

Contingency table used in the validation process.

\begin{tabular}{llllll}
\hline \multicolumn{5}{c}{ Forecasted } & \\
\hline & Fog & Mist & OK & \\
\hline \multirow{2}{*}{ Observed } & Fog & a & b & c & J \\
& Mist & d & e & f & K \\
& Clear & g & h & i & L \\
& & M & N & O & T \\
\hline
\end{tabular}

from the 14 selected episodes during 2017, with a temporal resolution of $1 \mathrm{~h}$. During the study period, fog was recorded $16.2 \%$ of the time, whereas mist was present $27.4 \%$ of the time. Visibility was categorized as OK during the remaining hours examined in the validation (56.4\%).

\subsubsection{Quantitative validation}

First, we performed a quantitative validation for the variables $\mathrm{T}, \mathrm{Td}$, $\mathrm{RH}$ and WSP. The averages for the 14 episodes in the study period are shown in Table 4. Regarding $\mathrm{T}$ validation, all models showed slight underestimation $(-0.3 \leq$ BIAS $\leq-0.2)$, with MAE about $1{ }^{\circ} \mathrm{C}$. The temporal correlation of $\mathrm{T}$ throughout the diurnal cycle is satisfactory, as shown by values of $r \geq 0.92$. Comparing the models, H38 and H40 were slightly better than WRF in the estimation of T at GCXO. Maximum temperature was simulated early during certain episodes by both $\mathrm{H} 38$ and $\mathrm{H} 40$, possibly causing earlier fog dissipation in the simulations than in reality.

From the validation of Td, BIAS values indicate moderate underestimation was detected for all the mesoscale models, with $\mathrm{MAE}=1.6^{\circ} \mathrm{C}$ for $\mathrm{H} 38$ and $\mathrm{H} 40$, and slightly larger for the WRF (MAE $=1.8^{\circ} \mathrm{C}$ ). The temporal correlation is very good for all cases $(r \geq 0.84)$, although slightly weaker than that of T. Similar results were obtained for RH, with general moisture underestimation by the mesoscale models for GCXO. MAE values of $9 \%-10 \%$ were obtained, and temporal correlation was very disappointing $(0.43 \geq r \geq 0.54)$. The most accurate model in the estimation of $\mathrm{Td}$ and $\mathrm{RH}$ near GCXO was H38, closely followed by H40. The best temporal correlation in Td estimation with respect to $\mathrm{RH}$ suggests the use of $\mathrm{Td}$ output by the mesoscale models as a moisture indicator for GCXO.

Regarding WSP, there was slight underestimation from the H38 model and moderate underestimation by the WRF. In contrast, the H40 model appeared to correct the WSP underestimation and was even characterized by slight overestimation (BIAS $=0.8 \mathrm{~m} / \mathrm{s}$ ), especially for strong wind episodes. Consequently, the MAE was smaller for H40 and larger for the WRF. The temporal correlation was satisfactory for both the H38 and $\mathrm{H} 40$ models ( $r=0.86$ and 0.90 , respectively), with poorer results from WRF. In general, predictability was greater for W and NW flows, which are characterized by strength and stability. However, the models were less reliable in estimating southerly component winds, because these are less strong. The models struggled with simulating changes in wind direction, especially when there was no marked pressure gradient. In the case of WSP, the H40 model clearly achieved the best results, followed closely by H38. The results of WRF are very disappointing.

Considering the TI, which considers all the variables as a whole, the $\mathrm{H} 38$ and H40 models stand out for their satisfactory results (with H40 slightly better). Those of the WRF are not very accurate. The poorer figures for the WRF model may be related to the cold-start used in its

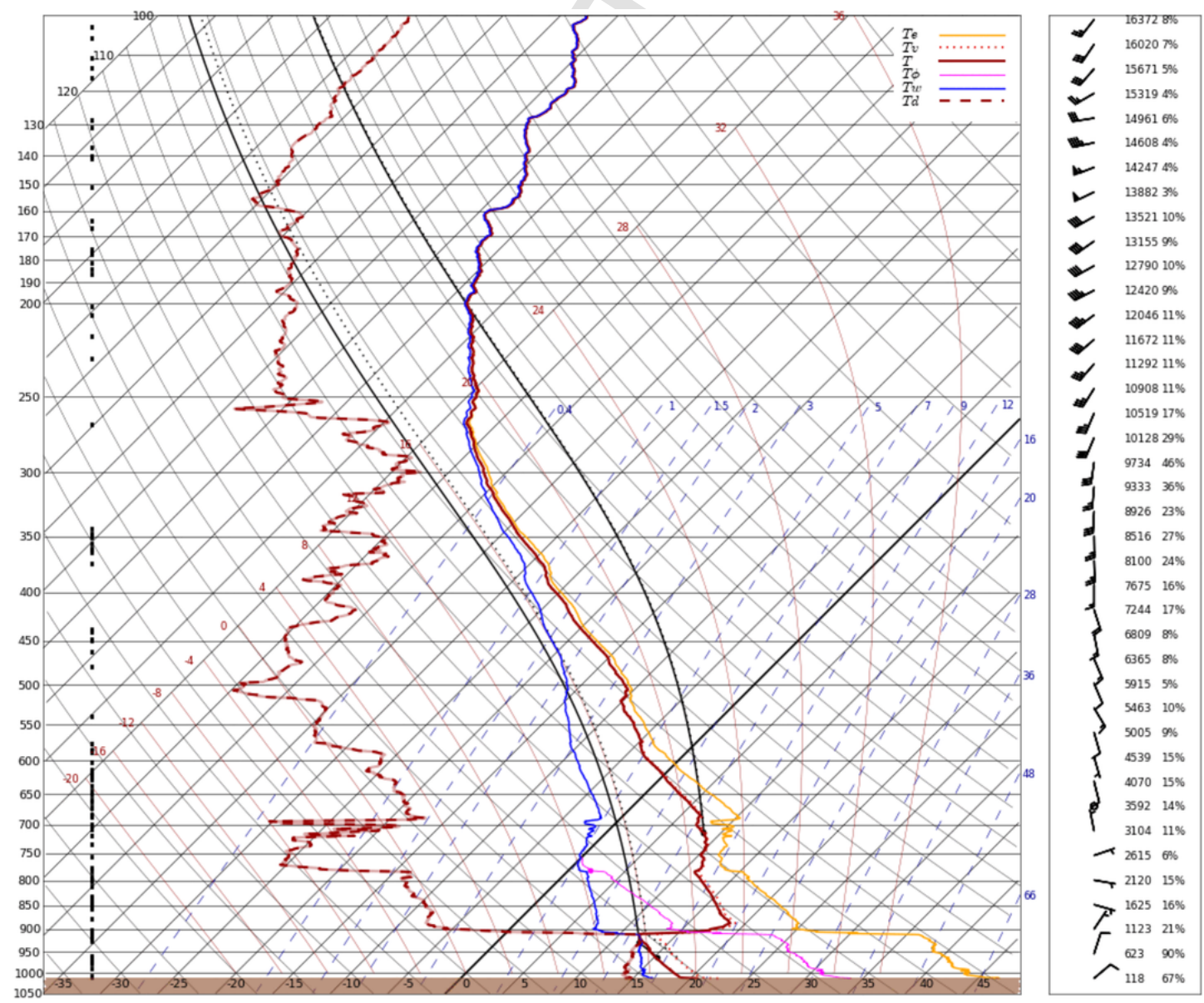

Fig. 2. Radiosonde data from island of Tenerife showing typical trade wind inversion. 

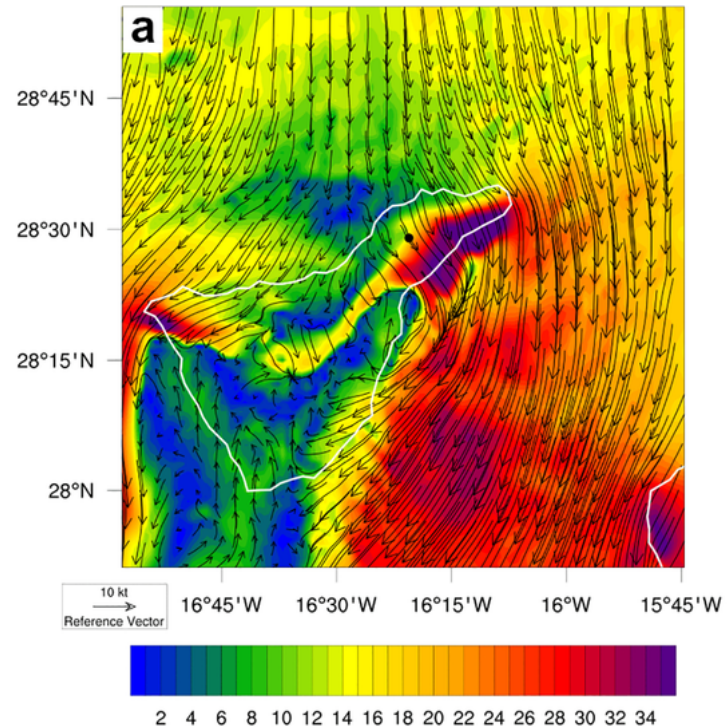
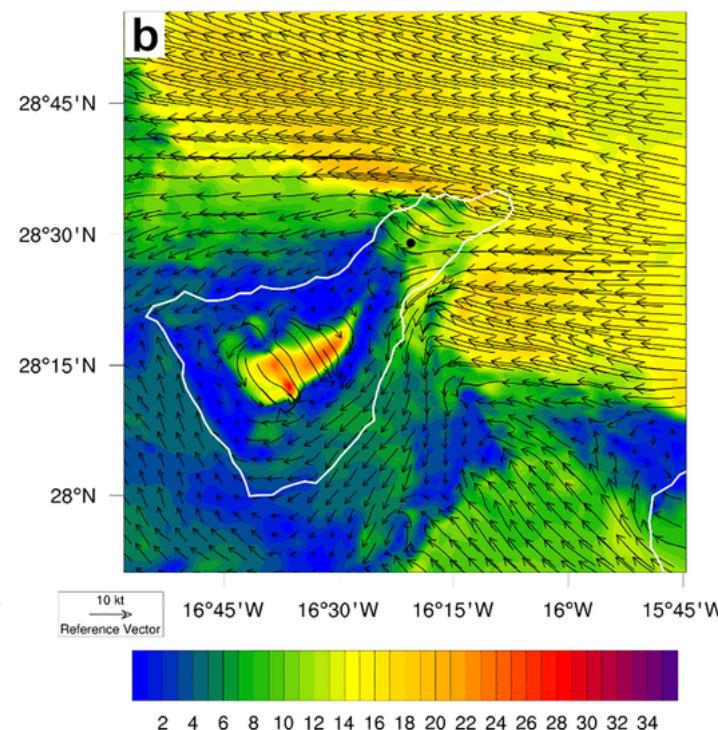

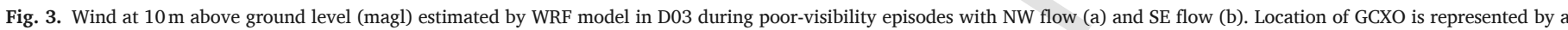
black dot.

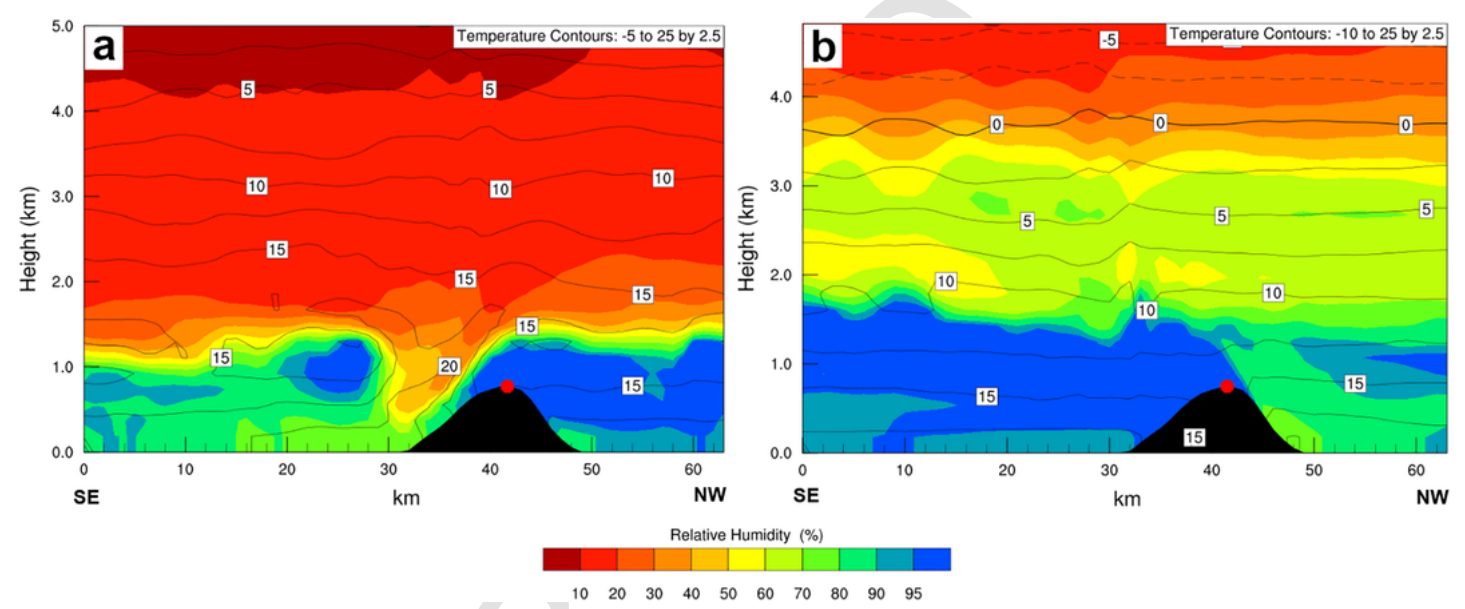

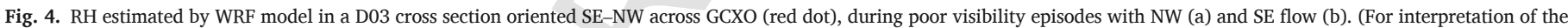
references to color in this figure legend, the reader is referred to the web version of this article.)

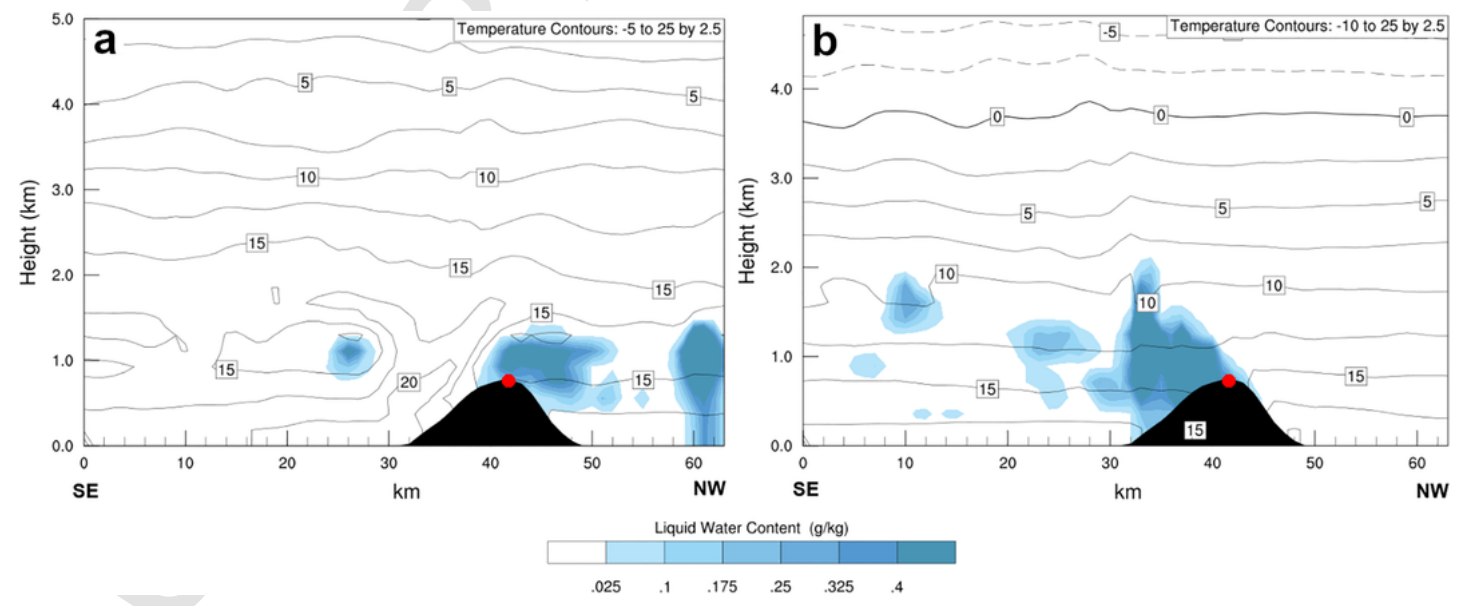

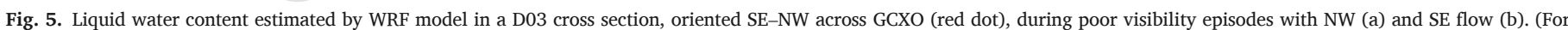
interpretation of the references to color in this figure legend, the reader is referred to the web version of this article.) 
Table 4

Results of the model validation for the variables T, Td, RH and WSP. The best results are highlighted in

\begin{tabular}{|c|c|c|c|c|c|c|c|c|c|c|c|c|}
\hline & WRF & & & & H38 & & & & $\mathrm{H} 40$ & & & \\
\hline & $\mathrm{T}$ & $\mathrm{Td}$ & $\mathrm{RH}$ & WSP & $\mathrm{T}$ & $\mathrm{Td}$ & $\mathrm{RH}$ & WSP & $\mathrm{T}$ & $\mathrm{Td}$ & RH & WSP \\
\hline BIAS & -0.3 & -1.6 & -6.0 & -2.0 & -0.2 & -1.3 & -5.2 & -1.0 & -0.2 & -1.4 & -5.9 & 0.8 \\
\hline MAE & 1.1 & 1.8 & 9.9 & 3.7 & 1.1 & 1.6 & 9.2 & 2.4 & 1.0 & 1.6 & 9.6 & 2.2 \\
\hline$r$ & 0.93 & 0.84 & 0.43 & 0.61 & 0.92 & 0.84 & 0.54 & 0.86 & 0.92 & 0.85 & 0.52 & 0.90 \\
\hline NI & 0.3 & 0.2 & 0.2 & 2.2 & -0.2 & -0.2 & -0.2 & 0.2 & -0.2 & -0.1 & 0.0 & -0.3 \\
\hline TI & 3.10 & & & & -0.50 & & & & -0.54 & & & \\
\hline
\end{tabular}

initialization and use of the GFS analysis for initial and boundary conditions. The better results for $\mathrm{H} 38$ and $\mathrm{H} 40$ may be attributed to a more complete assimilation system, in which observational data from a multitude of sources are considered. This corrected deviations from the previous model cycle to produce an analysis used as initial conditions in the warm start of the model.

\subsubsection{Multi-categorical validation}

Next, it was decided to execute a multi-categorical validation for testing model performance in estimating visibility. This decision was made after verifying that the results of a classical validation of a variable such as visibility gave results that were difficult to interpret. Visibility has drastic variations that can lead to large errors in numerical models, even though observed and forecast visibilities are not problematic for aviation operations. As previously mentioned, three categories were defined, depending on observed and model-estimated visibility values (fog, mist and OK). After developing respective contingency tables, the FBI, FAR and FOM were calculated. Table 5 shows results of the three mesoscale models and two methods of estimating visibility, i.e., using the algorithm based on moisture (VISRH) or that based on hydrometeor concentration (VISHD). Results of the WRF model are disappointing, especially for the large number of false alarms. The FOM was good when using the VISRH method, but showed substantial overestimation of poor-visibility episodes.

Regarding results of the two versions of the HARMONIE-AROME model, the outcomes were very similar when considering the VISRH method. The forecasts were balanced (FBI around 1.05), with FOM and FAR about 0.30 and 0.35 , respectively. For the VISHD method, we observed moderate overestimation of poor-visibility episodes from $\mathrm{H} 38$, but this led to a very favorable FOM (0.22). In contrast, H40 slightly underestimated poor-visibility events, thereby increasing the number of such events that were observed but not adequately predicted

Table 5

Results of the multi-categorical validation for the visibility based on T and RH (VISRH) and visibility based on hydrometeors concentration (VISHD).

\begin{tabular}{|c|c|c|c|c|c|c|}
\hline & WRF & & H38 & & $\mathrm{H} 40$ & \\
\hline & VISRH & VISHD & VISRH & VISHD & VISRH & VISHD \\
\hline FBI & 1.64 & 1.17 & 1.05 & 1.26 & 1.06 & 0.98 \\
\hline FAR & 0.56 & 0.51 & 0.34 & 0.38 & 0.36 & 0.37 \\
\hline FOM & 0.28 & 0.42 & 0.31 & 0.22 & 0.32 & 0.38 \\
\hline
\end{tabular}

Table 6

Results of the multi-categorical validation for the algorithms based on distinct thresholds of T-Td, RH and WSP.

\begin{tabular}{|c|c|c|c|c|c|c|c|c|c|c|c|c|}
\hline & OBSE & & & WRF & & & H38 & & & $\mathrm{H} 40$ & & \\
\hline & $\mathrm{A} 1$ & A2 & A3 & $\mathrm{A} 1$ & A2 & A3 & $\mathrm{A} 1$ & A2 & A3 & $\mathrm{A} 1$ & A2 & A3 \\
\hline FBI & 1.47 & 1.24 & 0.85 & 1.45 & 1.35 & 1.17 & 1.10 & 0.95 & 0.83 & 1.11 & 0.85 & 0.61 \\
\hline FAR & 0.36 & 0.28 & 0.22 & 0.55 & 0.52 & 0.48 & 0.38 & 0.33 & 0.29 & 0.37 & 0.32 & 0.30 \\
\hline FOM & 0.06 & 0.11 & 0.34 & 0.35 & 0.35 & 0.39 & 0.31 & 0.36 & 0.41 & 0.30 & 0.42 & 0.57 \\
\hline
\end{tabular}

$(\mathrm{FOM}=0.38)$. The FAR was similar for both versions of HARMONIE-AROME and both methods (0.34-0.38), markedly improving the results of WRF.

Because the present work focused on providing operational forecasters tools to maximize aviation safety during poor-visibility episodes, the aim was to minimize the FOM, because unforeseen fog events can pose a risk to aviation. Although it is also necessary to minimize the FAR, a greater number of false alarms would activate the poor-visibility protocol of GCXO and not pose an immediate risk to air safety. Nilo et al. (2018) obtained similar results $(\mathrm{FAR}=0.31$, FOM $=0.30$ ) for a nowcasting system based on satellite observations, but our forecasting system is able to predict fog $24 \mathrm{~h}$ in advance. This demonstrates that the results of $\mathrm{H} 38$ and $\mathrm{H} 40$ are satisfactory, especially considering the challenge of forecasting localized meteorological phenomena such as mist and fog in complex terrain. The validation was developed exclusively using data of poor-visibility episodes, which pose a greater challenge.

Analyzing the forecasts for each day of the study period individually, it was detected that the performance of both versions of the HARMONIE-AROME model was case-dependent, because on some days the H38 was more accurate in visibility estimation, whereas for other episodes $\mathrm{H} 40$ yielded superior results. For this reason, and taking into account that the validation results of both versions of HARMONIE-AROME are similar, it was decided to use both models and the two methods in the operational forecasting system. Thus, the operational forecaster would have four different visibility estimates from which to infer the risk of poor visibility at GCXO, as well as having a measure of forecast uncertainty according to the ratio of products that consider whether fog will form in the study area.

In addition to considering the VISRH and VISHD products, we validated three algorithms based on the exceedance of certain thresholds of $\mathrm{T}-\mathrm{Td}, \mathrm{RH}$ and WSP. Results of the algorithms are listed in Table 6. Visibility varied sharply in a few minutes at GCXO. This is the reason we also tested the algorithms with observed values, with the aim of applying them to the nowcasting of visibility.

As expected, best results were achieved using the observational data. In this case, A2 produced the best results, with a FOM of only 0.11 . This algorithm slightly overestimates poor-visibility episodes $(\mathrm{FBI}=1.24)$, leading to $\mathrm{FAR}=0.28$. The other algorithms were discarded because A1 markedly overestimated the number of such episodes, whereas A3 showed notable underestimation. A2 results are outstanding compared with similar nowcast products (Guijo-Rubio et al., 2018). 
Regarding the algorithms applied to mesoscale models, the worst results were once again obtained by the WRF model because of excessive overestimation of poor-visibility events, yielding for every algorithm a FAR around 0.50 . To prioritize air safety, it was decided to choose the algorithm that minimized FOM. As a result, A1 was chosen for both versions of the HARMONIE-AROME model. This algorithm had slight overestimation of poor-visibility episodes, with very satisfactory values of FAR and FOM (around 0.37 and 0.30 , respectively). The results of A1 for $\mathrm{H} 38$ and $\mathrm{H} 40$ are similar to those obtained by the VISRH and VISHD products from the same mesoscale models, so its use can be complementary, with the performance of each method superior for certain episodes or circumstances (e.g., wind direction and season).

Per the validation results, the use of A2 is recommended for the system based on observational data, and A1 is proposed for the H38 and H40 versions of the HARMONIE-AROME model. The WRF setting used in this research is not capable of simulating accurately poor visibility episodes in this emplacement, but further research would be convenient to find out if the results improve by using other physical parameterizations.

Because visibility forecasts are sensitive to both moisture quantity and the predicted mass concentrations of hydrometeors (Bang et al., 2008), all methods described in this paper are valid. Because the validation results are similar (and very accurate) for VISRH, VISHD and the algorithms based on thresholds, all those methods are adequate for forecasting poor visibility episodes at GCXO.

\subsection{Forecast system}

A poor-visibility episode on 13 December 2018 was selected to show the potential of the forecast applications developed in our research. First, information provided by mesoscale models was used to elaborate the products for a short-term forecast. These forecast products are oriented to the creation of TAF reports, with a lead time out to $24 \mathrm{~h}$. Then, several satellite products were used to aid the development of TREND reports and potentially inform about errors in the model forecasts.

\subsubsection{Short-term forecast}

According to the validation results, use of the WRF model was rejected for operational forecast. Because the validation results for the H38 and H40 models are very similar, it was decided to use both. Likewise, we considered the two methods to estimate visibility (VISRH and VISHD). Thus, a greater amount of information is made available and our prediction system therefore more robust.

Fig. 6 shows visibility estimated by the H38 and H40 models using the VISRH and VISHD methods for a poor-visibility episode character-
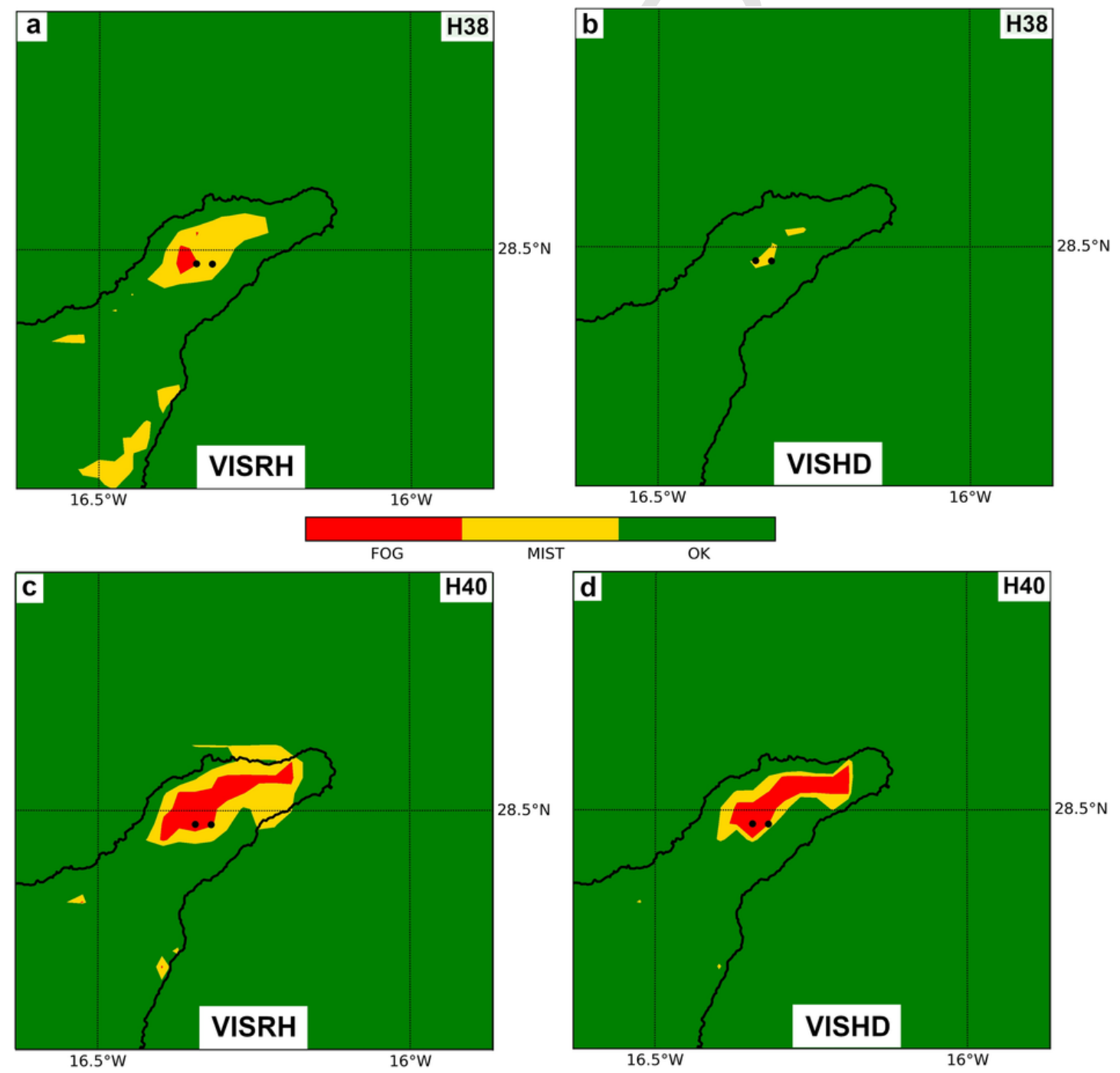

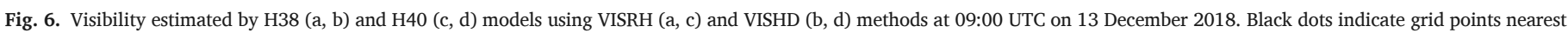
the locations of GCXO R12 (left) and R30 (right). 
ized by a NW wind. In this example, the airport had reduced visibility especially at R12 but also affecting R30. Unlike the H40 model, H38 did not reproduce the drastic reduction of visibility in this case, simulating only a risk of mist in the vicinity of GCXO.

Regarding differences between the two methods, the visibility reduction was sharper in the case of VISHD, going from visibility OK to fog, with almost no areas of mist. The reduction was progressive using the VISRH method.

The spread between models and methods to estimate visibility can be interpreted as a measure of the predictability of an episode. For instance, when fog is forecast by both models and methods, the forecaster can be reasonably sure that poor visibility will occur. However, when there are discrepancies between the various visibility estimates (as in the case of Fig. 6), the reliability of the predictive system is poorer and associated forecast uncertainty is greater.

In addition to the short-term forecast products, $\mathrm{T}-\mathrm{Td}$, $\mathrm{RH}$, wind direction and WSP fields estimated by $\mathrm{H} 38$ and $\mathrm{H} 40$ were also generated for supporting the decision-making process for constructing TAF and TREND reports. Vertical profiles of T, Td and wind forecasts by the HARMONIE-AROME model at the nearest grid point to each of the GCXO runways are also available to the operational forecaster to provide information equivalent to radiosonde observations.

\subsubsection{Nowcasting}

Ultimately, the use of satellite products is proposed for the nowcasting of poor-visibility episodes at GCXO. It is thereby possible to complement the information from the mesoscale models or have another source of information when the models are not accurate. In addition, the product obtained from the algorithm based on thresholds is described.

An image of the Cloud Type product is presented in Fig. 7, which allows differentiation between low, medium, and high clouds, as well as between thin and thick clouds. The accuracy of this product was substantiated by the verification of Karlsson and Dybbroe (2010). The product can be complemented by the Cloud Top Altitude product (Fig. 8), which furnishes information about cloud-top altitude in feet (ft). Poor-visibility episodes at GCXO are related to stratocumulus, which are identified as low or very low clouds in the Cloud Type product, commonly with cloud-top altitude below $6000 \mathrm{ft}$. When the trade

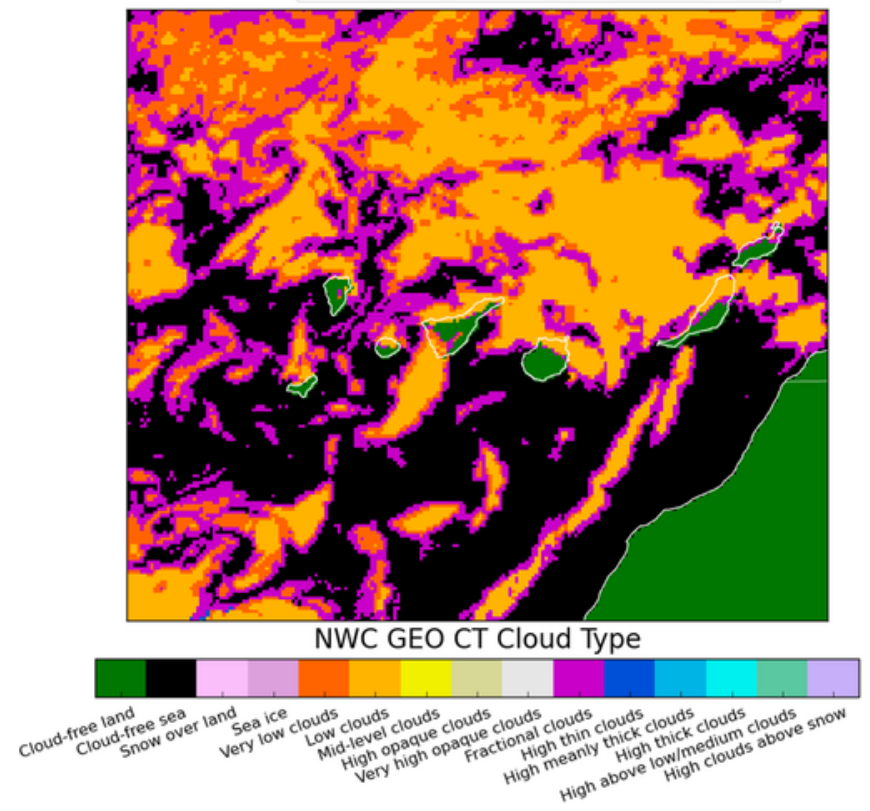

Fig. 7. Image of Cloud Type product of NWC SAF during poor-visibility episode characterized by NW flow. Copyright 2018 EUMETSAT.

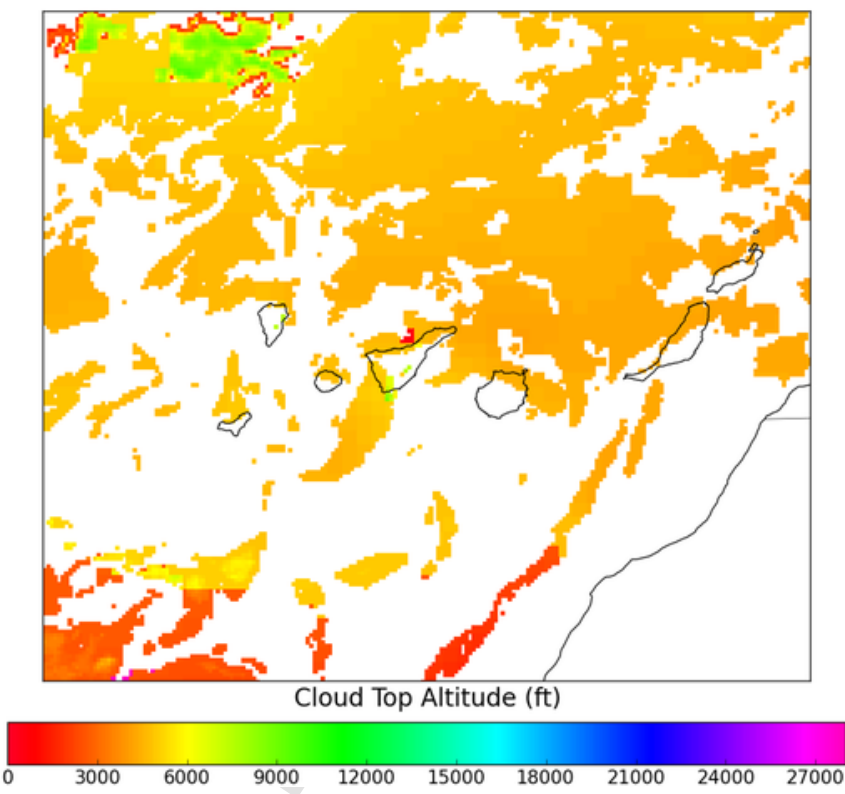

Fig. 8. Image of Cloud Top Altitude product of NWC SAF during poor-visibility episode characterized by NW flow. Copyright 2018 EUMETSAT.

winds prevail as in the case shown by Figs. 7-9, low clouds usually form north of Tenerife island, which may affect visibility at GCXO. The altitude estimated by the aforementioned product is very reliable because it was tested following the methodology in Karlsson and Johansson (2013).

Finally, Fig. 9 shows an example of images generated by the Precipitable Water in Boundary Layer NWC SAF product over the Canary Islands. In accord with monitoring during the months of the project, precipitable water in the PBL in excess of $10 \mathrm{~mm}$ is necessary for low cloud development in the study area, which can lead to episodes of poor visibility at GCXO. The risk of such episodes increases when precipitable water in the PBL is $>15 \mathrm{~mm}$. The main limitation of the product is that it is not available for areas covered by clouds. However, be-

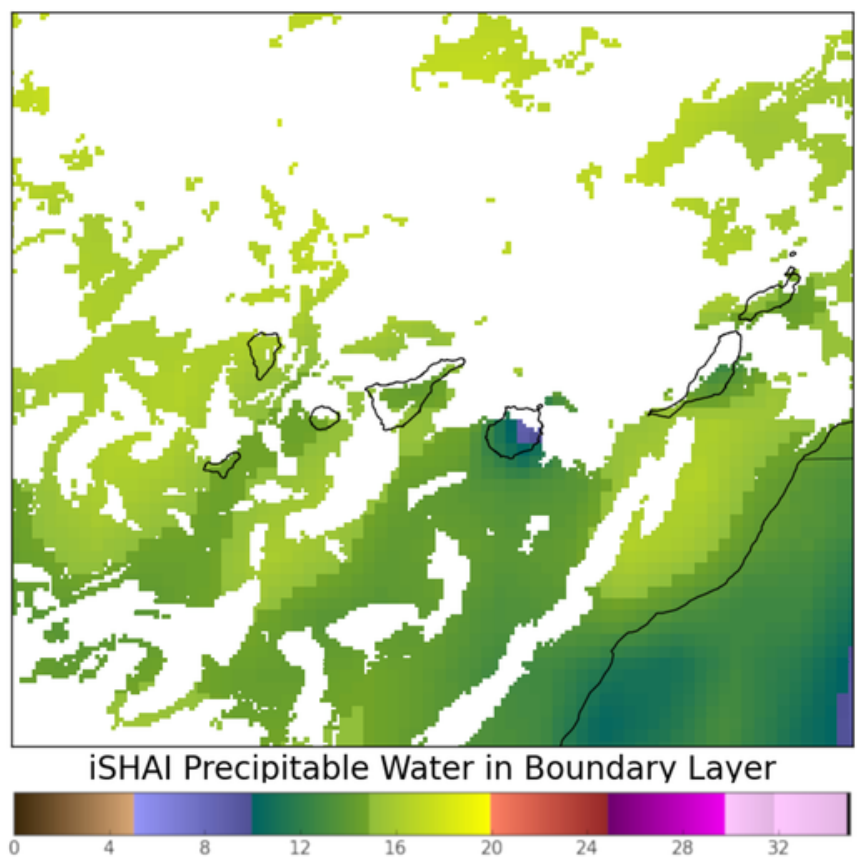

Fig. 9. Image of Precipitable Water in Boundary Layer product of NWC SAF during poor-visibility episode characterized by NW flow. Copyright 2018 EUMETSAT. 
cause variations of precipitable water in the PBL are slight over large regions, the product can reliably estimate water content in the study area and in air masses approaching the Canary Islands, even when there are large areas covered by cloudiness.

Finally, a tool was developed for indicating inferred visibility by color-coding the runway threshold (OK: green; mist: yellow; fog: red) based on if certain values of the variables T, Td, RH and WSP defined in Table 2 are exceeded. In this way, an algorithm is developed to decide the color-coding of each runway threshold on the application developed for the operational forecasters. Owing to the particular characteristics of fog, it requires sufficient kinetic energy provided by the wind, which is transformed into potential energy during air mass ascent along the slope of the hill on which GCXO is situated. A large moisture amount is also needed so that the adiabatic cooling experienced during the ascent condenses the water vapor contained in the air mass. The tool was developed to complement the mesoscale models and satellite products, with a focus on nowcasting. Because visibility in the study area changes very rapidly, this tool is intended to anticipate such changes on a short scale of a few minutes. For this reason, the monitoring of real-time observations can facilitate anticipation of a change in weather that forms fog in the study area.

The aim of the above application is to alert regarding the risk of mist or fog when certain observed conditions are fulfilled. For observed conditions, A2 was selected in the validation, so this was used in development of the application. As seen in Fig. 10, the risk of poor visibility at R12 was indicated by the algorithm, because a NW wind stronger than $4 \mathrm{kt}$ was driving a moisture flow $(\mathrm{RH} \geq 97.5 \%)$ that reduced $\mathrm{T}-\mathrm{Td}$ to $<0.3^{\circ} \mathrm{C}$. In this example, as is usually the case during NW wind episodes, visibility conditions were better at R30, where only the risk of mist was indicated by the algorithm.

\section{Conclusions}

Visibility forecasts in the vicinity of airports are vital to maximize aviation safety. However, this task is not easy for numerical weather prediction models, especially for airports in complex terrain such as GCXO. In such cases, the use of high-resolution mesoscale models is essential to attain accurate visibility forecasts. The main conclusions of our research are as follows.

- Poor visibility episodes in the vicinity of GCXO are related to trade winds and a thermal inversion favored by the semi-permanent subtropical high. At the mesoscale, trade winds are channeled through a mountain pass where the airport is located, and the air mass (which is typically moisture-laden after crossing the Atlantic Ocean) is forced

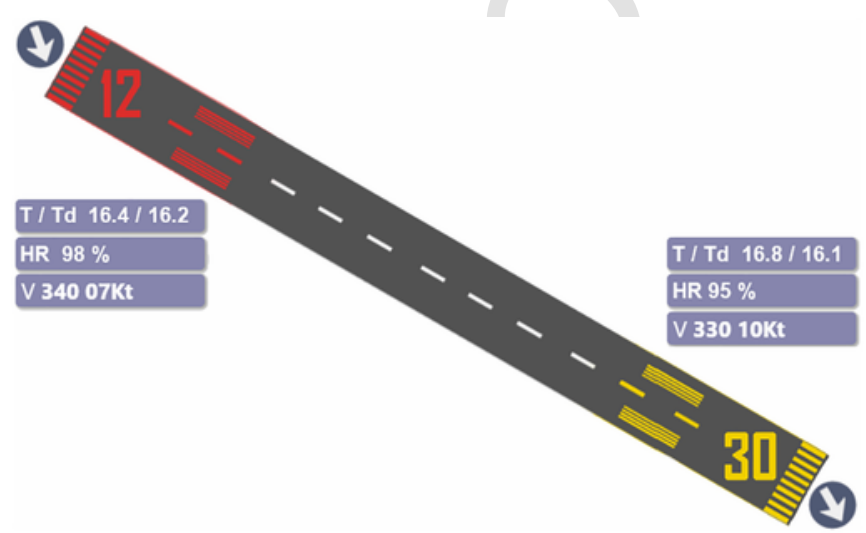

Fig. 10. Application for inferring visibility from algorithm based on observed thresholds of T-Td, RH and WSP. to ascend and cool adiabatically. When all factors are favorable, condensation is reached, forming low clouds in the study area.

- Validation results of the H38 and H40 versions of HARMONIE-AROME are satisfactory, especially for the variables T and WSP. The models struggled with predicting variables related to humidity, but Td values were accurately predicted. The performance of the methods proposed herein for estimating visibility was outstanding, especially considering the local scale at which the analyzed meteorological phenomenon develops, the complex terrain in which the airport is located, and the poor predictability of the episodes selected as samples in the validation.

- Using the numerical weather prediction models, there is no single method for estimating visibility that is clearly optimal at GCXO for every poor-visibility episode. Consequently, a combination of information provided by several methods may be useful, facilitating the evaluation of uncertainty associated with the forecast of a specific episode.

For nowcasting, the use of products based on satellite images is greatly encouraged, because they can provide information on moisture content in the PBL and alerts of the formation of low clouds around the Canary Islands.

- The application developed from the algorithm based on observed variables may allow the monitoring of realtime observations, enabling forecasters to anticipate weather conditions favorable to fog development.

In conclusion, the short-term and nowcasting products proposed in this research may improve safety at GCXO and be applied to other airports affected by low-visibility episodes, after analyzing specific characteristics of the fog that develops at each location. This could be the objective of future work, examining which airports are also affected by poor visibility and adapting the tools developed herein to the needs of each aerodrome.

\section{Acknowledgements}

This work was supported by the Aeronautics Annual Plan 2018 of AEMET. Special thanks go to projects SAFEFLIGHT (CGL2016-78702-C2-1-R and CGL2016-78702-C2-2-R) and UE ERA-NET Plus NEWA (PCIN2016-080).

\section{References}

AEMET, 2019. Climatología aeronáutica del aeropuerto de Tenerife Norte/Los Rodeos. http://ama.aemet.es/documents/19/48901/GCXO.pdf.

Ahmed, R., Dey, S., Mohan, M., 2015. A study to improve night time fog detection in the indo-gangetic basin using satellite data and to investigate the connection to aerosols. Meteorol. Appl. 22, 689-693. https://doi.org/10.1002/met.1468.

Baldwin, M.E., Kain, J.S., 2006. Sensitivity of several performance measures to displacement error, bias, and event frequency. Weather Forecast. 21 (4), 636-648. https:// doi.org/10.1175/WAF933.1.

Bang, C.H., Lee, J.W., Hong, S.Y., 2008. Predictability experiments of fog and visibility in local airports over Korea using the WRF model. J. Korean Soc. Atmos. Env. 24, 92-101.

Bengtsson, L., Andrae, U., Aspelien, T., Batrak, Y., Calvo, J., de Rooy, W., Gleeson, E., Sass, B.H., Homleid, M., Hortal, M., et al., 2017. the harmonie-arome model configuration in the ALADIN-HIRLAM NWP system. Mon. Weather Rev. 145, 1919-1935. https:// doi.org/10.1175/MWR-D-16-0417.1.

Bergot, T., Terradellas, E., Cuxart, J., Mira, A., Liechti, O., Mueller, M., Nielsen, N.W., 2007. Intercomparison of single-column numerical models for the prediction of radiation fog. J. Appl. Meteorol. Climatol. 46, 504-521. https://doi.org/10.1175/ JAM2475.1.

Brousseau, P., Berre, L., Bouttier, F., Desroziers, G., 2011. Background-error covariances for a convective-scale data-assimilation system: AROME-France 3DVar. Q. J. R.Meteorol. Soc. 137, 409-422. https://doi.org/10.1002/qj.750.

Buizza, R., Miller, M., Palmer, T., 1999. Stochastic representation of model uncertainties in the ECMWF Ensemble Prediction System. Q. J. R. Meteorol. Soc. 125 (560), 2887-2908. https://doi.org/10.1002/qj.49712556006.

Cermak, J., Bendix, J., 2008. A novel approach to fog/low stratus detection using Meteosat 8 data. Atmos. Res. 87, 279-292. https://doi.org/10.1016/j.atmosres.2007.11.009.

Chou, M.-D., Suárez, M.J., Liang, X.-Z., Yan, M.-H., 2001. A thermal infrared radiation parameterization for atmospheric studies. In: NASA Tech. Rep. Series on Global Mod- 
eling and Data Assimilation. vol. 19, Goddard Space Flight Center, (NASA/ TM-2001-104606, 56 pp).

Cuxart, J., Bougeault, P., Redelsperger, J.L., 2000. A turbulence scheme allowing for mesoscale and large-eddy simulations. Q. J. R. Meteorol. Soc. 126, 1-30. https://doi. org/10.1002/qj.49712656202.

Dee, D.P., Uppala, S.M., Simmons, A.J., Berrisford, P., Poli, P., Kobayashi, S., Andrae, U., Balmaseda, M.A., Balsamo, G., Bauer, P., et al., 2011. The ERA-Interim reanalysis: Configuration and performance of the data assimilation system. Q. J. R. Meteorol. Soc. 137, 553-597. https://doi.org/10.1002/qj.828.

Dey, S., 2018. On the theoretical aspects of improved fog detection and prediction in India. Atmos. Res. 202, 77-80. https://doi.org/10.1016/j.atmosres.2017.11.018.

Doran, J.A., Roohr, P.J., Beberwyk, D.J., Brooks, G.R., Gayno, G.A., Williams, R.T., Lewis, J.M., Lefevre, R.J., 1999. The MM5 at the Air Force Weather Agency-New products to support military operations. In: The 8th Conference on Aviation, Range, and Aerospace Meteorology, Dallas, Texas.

Evans, J.P., Ekström, M., Ji, F., 2012. Evaluating the performance of a WRF physics ensemble over south-East Australia. Climate Dyn. 39, 1241-1258. https://doi.org/10.1007/ s00382-011-1244-5.

Fedorova, N., Levit, V., da Silva, A.O., dos Santos, D.M.B., 2013. Low visibility formation and forecasting on the northern coast of Brazil. Pure Appl. Geophys. 170 (4), 689-709. https://doi.org/10.1007/s00024-012-0565-6.

Fernández-González, S., Martín, M.L., Merino, A., Sánchez, J.L., Valero, F., 2017. Uncertainty quantification and predictability of wind speed over the Iberian Peninsula. J. Geophys. Res. Atmos. 122, 3877-3890. https://doi.org/10.1002/2017JD026533.

Fischer, C., Montmerle, T., Berre, L., Auger, L., Stefanescu, S.E., 2005. An overview of the variational assimilation in the ALADIN/France numerical weather-prediction system. Q. J. R. Meteorol. Soc. 613, 3477-3492. https://doi.org/10.1256/qj.05.115.

Guijo-Rubio, D., Gutiérrez, P.A., Casanova-Mateo, C., Sanz-Justo, J., Salcedo-Sanz, S., Hervás-Martínez, C., 2018. Prediction of low-visibility events due to fog using ordinal classification. Atmos. Res. 214, 64-73. https://doi.org/10.1016/j.atmosres.2018. 07.017.

Gultepe, I., Tardif, R., Michaelides, S.C., Cermak, J., Bott, A., Bendix, J., Müller, M.D., Pagowski, M., Hansen, B., Ellrod, G., Jacobs, W., Toth, G., Cober, S.G., 2007. Fog research: a review of past achievements and future perspectives. Pure Appl. Geophys. 164 (6-7), 1121-1159. https://doi.org/10.1007/s00024-007-0211-x.

Masson, V., 2016. The Externalized Surface User's Guide v7.3; Tech. Report; Meteo France: Toulouse, France. Available online http://www.umr-cnrm.fr/surfex/spip. php?rubrique10, (accessed on 4 December 2018).

Janjic, Z.A., 1990. The step-mountain coordinate: physics package. Mon. Weather Rev. 118, 1429-1443.

Johnson, A., Wang, X., 2012. Verification and calibration of neighborhood and object-based probabilistic precipitation forecasts from a multimodel convection-allowing ensemble. Mon. Wea. Rev. 140, 3054-3077. https://doi.org/10.1175/MWR-D-1100356.1.

Karlsson, K.G., Dybbroe, A., 2010. Evaluation of Arctic cloud products from the EUMETSAT Climate Monitoring Satellite Application Facility based on CALIPSO-CALIOP observations. Atmos. Chem. Phys. Discuss. 9, 16755-16810. https://doi.org/10.5194/ acp-10-1789-2010.

Karlsson, K.G., Johansson, E., 2013. On the optimal method for evaluating cloud products from passive satellite imagery using CALIPSO-CALIOP data: example investigating the CM SAF CLARA-A1 dataset. Atmos Meas. Tech. 6, 1271-1286. https://doi.org/ 10.5194/amt-6-1271-2013.

Kunkel, B.A., 1984. Parameterization of droplet terminal velocity and extinction coefficient in fog models. J. Clim. Appl. Meteorol. 23, 34-41. https://doi.org/10.1175/ 1520-0450(1984)023<0034:PODTVA > 2.0.CO;2.

Lenderink, G., Holtslag, A., 2004. An updated length-scale formulation for turbulent mixing in clear and cloudy boundary layers. Q. J. R. Meteorol. Soc. 130, 3405-3427. https://doi.org/10.1256/qj.03.117.

López, L., García-Ortega, E., Sánchez, J.L., 2007. A short-term forecast model for hail. Atmos. Res. 83, 176-184. https://doi.org/10.1016/j.atmosres.2005.10.014.
Masson, V., Le Moigne, P., Martin, E., Faroux, S., Alias, A., Alkama, R., Belamari, S., Barbu, A., Boone, A., Bouyssel, F., et al., 2013. The SURFEXv7. 2 land and ocean surface platform for coupled or offline simulation of earth surface variables and fluxes. Geosci. Model Dev. 6, 929-960. https://doi.org/10.5194/gmd-6-929-2013.

Nielsen, K.P., Gleeson, E., 2018. Using Shortwave Radiation to Evaluate the HARMONIE-AROME Weather Model. Atmosphere 9 (163), 1-16. https://doi.org/10.3390/ atmos9050163.

Nielsen, K.P., Gleeson, E., Rontu, L., 2014. Radiation sensitivity tests of the HARMONIE 37h1 NWP model. Geosci. Model Dev. 7, 1433-1449. https://doi.org/10.5194/gmd7-1433-2014.

Nilo, S.T., Romano, F., Cermak, J., Cimini, D., Ricciardelli, E., Cersosimo, A., Di Paola, F., Gallucci, D., Gentile, S., Geraldi, E., Larosa, S., Ripepi, E., Viggiano, M., 2018. Fog detection based on Meteosat Second Generation-Spinning enhanced visible and infrared imager high resolution visible channel. Remote Sens. 10 (4), 541. https://doi.org/10. 3390/rs10040541.

Pagowski, M., Gultepe, I., King, P., 2004. Analysis and modeling of an extremely dense fog event in southern Ontario. J. Appl. Meteorol. 43 (1), 3-16. https://doi.org/10.1175/ 1520-0450(2004)043<0003:AAMOAE > 2.0.CO;2.

Payra, S., Mohan, M., 2014. Multirule based diagnostic approach for the fog predictions using WRF modelling tool. Adv. Meteorol. 2014, 456065. https://doi.org/10.1155/ 2014/456065.

Petersen, C., Nielsen, N.W., 2000. Diagnosis of visibility in DMI-HIRLAM. In: DMI Scientific Report 00-11, pp 37. DMI, Copenhagen, Denmark, Available from.

Rípodas, P., Legleau, H., Kerdraon, G., Moisselin, J.M., Autones, F., García Pereda, J., Martínez, M.A., Marcos, C., Jann, A., Wirth, A., Calbet, X., Alonso, O., Ariza, C., 2016. NWC SAF GEO v2016. New products, changes and improvements. Proceedings for the 2016 EUMETSAT Meteorological Satellite Conference, Darmstadt, Germany.

da Rocha, R.P., Gonçalves, F.L., Segalin, B., 2015. Fog events and local atmospheric features simulated by regional climate model for the metropolitan area of São Paulo. Brazil. Atmos. Res. 151, 176-188. https://doi.org/10.1016/j.atmosres.2014.06.010.

Saha, S., et al., 2010. The NCEP climate Forecast System Reanalysis. Bull. Amer. Meteor. Soc. 91, 1015-1057. https://doi.org/10.1175/2010BAMS3001.1.

Sánchez Arriola, J., Lindskog, M., Thorsteinsson, S., Bojarova, J., 2016. Variational bias correction of GNSS ZTD in the HARMONIE modeling system. J. Appl. Meteorol. Climatol. 55 (5), 1259-1276. https://doi.org/10.1175/JAMC-D-15-0137.1.

Seity, Y., Brousseau, P., Malardel, S., Hello, G., Benard, P., Bouttier, F., Lac, C., Masson, V., 2011. The AROME France convective-scale operational model. Mon. Wea. Rev. 139, 976-991. https://doi.org/10.1175/2010MWR3425.1.

Skamarock, W.C., Klemp, J.B., 2008. A time-split nonhydrostatic atmospheric model for weather research and forecasting applications. J. Comput. Phys. 227, 3465-3485. https://doi.org/10.1016/j.jcp.2007.01.037.

Stensrud, D., Bao, J.-W., Warner, T., 2000. Using initial condition and model physics perturbations in short-range ensemble simulations of mesoscale convective systems. Mon. Weather Rev. 128, 2077-2107. https://doi.org/10.1175/1520 0493(2000)128<2077:UICAMP > 2.0.CO;2.

Stoelinga, M.T., Warner, T.T., 1999. Nonhydrostatic, mesobeta-scale model simulations of cloud ceiling and visibility for an East Coast winter precipitation event. J. Appl. Meteorol. 38, 385-404.

Stolaki, S., Pytharoulis, I., Karacostas, T., 2012. A study of fog characteristics using a coupled WRF-COBEL model over Thessaloniki Airport, Greece. Pure Appl. Geophys. 169 (5-6), 961-981. https://doi.org/10.1007/s00024-011-0393-0.

Thompson, G., Field, P.R., Rasmussen, R.M., Hall, W.D., 2008. Explicit forecasts of winter precipitation using an improved bulk microphysics scheme. Part II: Implementation of a new snow parameterization. Mon. Wea. Rev. 136, 5095-5115. https://doi.org/10. 1175/2008MWR2387.1.

WMO, 2011. Manual on Codes, International Codes. Technical Report. World Meteorological Organization. 